\title{
Expectation of administering the first aid for traumatic victims during the absence of pre-hospital service
}

\author{
Fitri Anita ${ }^{1}$, Tita Hariyanti ${ }^{2}$, Tony Suharsono ${ }^{3}$ \\ ${ }^{1}$ Master Program of Nursing, Faculty of Medicine, Universitas Brawijaya, Indonesia \\ ${ }^{2}$ Master Program of Hospital Management, Faculty of Medicine, Universitas Brawijaya, Indonesia \\ ${ }^{3}$ Department of Emergency Nursing, Faculty of Medicine, Universitas Brawijaya, Indonesia
}

\begin{tabular}{l} 
Article Info \\
\hline Article history: \\
Received Jun 7, 2020 \\
Revised Nov 21, 2020 \\
Accepted Jan 2, 2021 \\
\hline
\end{tabular}

\section{Keywords:}

Emergency state

Expectation

Pre-hospital administration

Traffic accidents

\begin{abstract}
Traffic incidents become typical cases of trauma outside of hospitals. The integrated-emergency nursing system outside of hospitals becomes an important component to minimize any worsening condition of the traumatic victims. However, this pre-hospitalized service system has not been formally established in several cities or municipalities. This research aims to explore various hopes of the trauma-victim aid process in a region that has not applied pre-hospitalized emergency service formally. This research was carried out by implementing a qualitative research method and a case study approach to identify the themes. The research was conducted in Konawe municipality, from February until March 2020. It was done by interviewing eight participants consisting of the citizens, traffic police officers, hospital party, and health agency. Four themes result from this research. Establishing the pre-hospitalized emergency service, socializing the first aid for the incident victims, training dealing with the first aid of taking care of trauma victims, and promoting socialization for all citizens about the emergency numbers of health service institutions which could be immediately contacted when an accident occurs. There is a need for an emergency service system establishment and development.
\end{abstract}

This is an open access article under the CC BY-SA license.

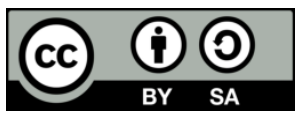

\section{Corresponding Author:}

Fitri Anita

Master Program of Nursing, Faculty of Medicine

Universitas Brawijaya, Malang, Indonesia

Email: fitrianita.demara@gmail.com

\section{INTRODUCTION}

An emergency state is a situation that unpredictably occurs at any time. Such emergency state cases that are not immediately taken care of would cause damages to the organs. It will rise to disability or mortality. This condition lowers productivity and increases the cost that directly influences the economic status and psychosocial aspects of the sufferers and their families. Traffic incidents, diseases, fires, or other natural disasters become several conditions that could cause emergency state situations [1]. Traffic incidents become the most frequent causes of emergency state conditions [2].

Traffic incidents become serious problems to cause trauma [3]. Each year, globally, it is noted 50 million injury cases with 1.2 million mortality rates due to traffic incident trauma [2]. According to the Indonesian Police Traffic Corps, averagely, 3 persons are found dead due to traffic incidents hourly. In 2018, it was noted $28.535 \%$ of traffic incidents with $6.202 \%$ death victims [4]. Traffic incidents that cause many victims need immediate aids on the spot [5].

Providing initial aid outside of the hospital (pre-hospital care) influences the survivability and mortality of the traumatic victims [6]. Pre-hospital care is generally interpreted as the external care of 
hospitals. It becomes an acute and emergency care and is administered outside of health facilities, such as hospitals or clinics [7]. It is stated that the mortality rate due to trauma occurring outside of the hospital could be higher as found in the regions. Moreover when the regions do not have an emergency care system [8].

The aid administration in the pre-hospital phase is expected to be applicable quickly and accurately by the professionals. When the victims are sent off to the hospital immediately, they will have higher survivability rates [9]. It is said that response time for the victims is lesser than 60 minutes until they arrive in the health service. Therefore, that lateness for more than 60 minutes would worsen the impacts of the suffered injuries [10]. The facts in some regions are when traffic incidents occur, those who administer the firs aid (first responder) are not trained medical professionals but instead common people or surrounding citizens near to the incident location. Common and untrained people become the most frequent observers who arrive and gather around the accident location [10,11]. The common people arriving in the locations are such as relatives, local public figures, bikers, public transportation drivers or cap drivers, and police officers [10].

While an accident occurs, there is an initial action to promote by the first responders that arrive in the accident location. Activating an emergency call becomes the most required action at the beginning [2]. Activating the emergency call increases the time of the trauma victim responses in obtaining professional care from medical workers and safe transportation to the hospital [12]. It will be realized if the emergency service outside of hospitals lasts formally in the integrated emergency management system (IEMS). One of the regions that have not had any emergency service system outside of the hospital formally is Konawe municipality, Southern East Sulawesi, Indonesia.

Uncoordinated service management will worsen the emergency service [13]. This condition causes the absence of contactable call to get the medical worker aids. The citizens around the accident location should go to the health service or police station for asking for help. It takes time due to covering the distance. The common people have to stop any passing vehicles in the accident spot or to collect money for renting a personal vehicle to send off the victims to health service facilities [6]. This condition is frequently found by society with insufficient knowledge and skill. Thus, people could not do anything or spend a long time committing any trivial actions for the victims [6]. Because of such conditions, it makes the emergence of expectancy of various parties in providing first aid for traumatic victims in the region without any support from formal pre-hospital services. This research focuses to explore various hopes of the trauma-victim aid process in a region that has not applied pre-hospitalized emergency service formally.

\section{RESEARCH METHOD}

This is a qualitative research method. Qualitative research methods are research conducted in the natural environment of object conditions by applying interpretive and naturalistic paradigms to the focus of research. The approach used in this research is the case study approach. This research was conducted in Konawe City. This research was conducted from February to March 2020. The time and place to promote interviews were adjusted to the objectives targeted in this qualitative study. The researchers and informants agreed on the place based on where the informant was at that time. All participants were interviewed after getting their agreement. Interviews with informants were carried out after fulfilling the time and place agreement for the informant's comfort and privacy. The in-depth interview method was carried out on eight participants (P1-P8) consisting of the people, police, hospital officers, and health workers in the research area who have experience in handling trauma cases due to traffic accidents.

Data collection procedures used is in-depth interviews and observation techniques. In-depth interviews were conducted using open and semi-structured questions. Before promoting the interview process, the researchers initially prepared several key questions to guide the interview. That was done to make it easier for researchers to conduct consistent interviews and collect data. The interview process is conducted for participants. It was then recorded using the researcher's voice recorder. Dealing with nonverbal reactions from informants and the atmosphere during the interview was written by the researchers on the field notes. All recordings are then transferred to a computer and analyzed. Each interview has been held for 30 to 40 minutes. Transcripts are coded manually to identify themes and sub-themes which are then categorized into categories. To increase the validity of the findings, it was later verified by other researchers.

\section{RESULTS AND DISCUSSION}

\subsection{Fostering pre-hospital service}

Fostering pre-hospital service becomes hopes from several participants. The emergence of intentions to foster an emergency service system has been existing since a long time ago. The intention to create prehospital services were not only based on the Health Minister that concerns with the integrated emergency 
management system (IEMS), but it emerged because of the observable experience from several victims' conditions that did not obtain more professional administration before the medical workers from a hospital arrived. The accident victims that did not get professional administration were worried to be at disadvantaged conditions. Therefore, by existence pre-hospital service, it is expected to lower morbidity rate as uttered below.

"It is. It means besides the existence of the Health Minister Regulation, Number (remembering for sometimes). Number 19 the Year 2016, Yes, it is. Started from a long ago, we have demanded to establish a pre-hospital system that is run formally. The reason is that many patients that the administration, I mean the patients outside of the hospital, that the administration is not appropriate with what we want. Sometimes, the occurrence of the traumas, such as cervical fracture, there were no provided cares from the society or officers. Even, it would worsen the condition so by this existence, based on our observation, we try to promote pre-hospital administration." (P1)

Besides the hospital party, the traffic unit party also provided the required empowerment that there was a need for an integrated pre-hospital service among the concerning institutions in the efforts to provide care for emergency cases. The integrated coordination with the health team was expected to create better results toward the victims' conditions as uttered here:

"There would be a need for coordination to create an integrated team._This integrated team creation would be useful when a traffic accident occurs. They could handle it together. There would be also police officers and hospital professionals as well as the safer ambulance to get ready." (P5)

The integrated pre-hospital service in a coordinated system has become the focus of the government. The health service system coordination is mentioned in the integrated emergency management system (IEMS) with its PSC 119 program. In this research, the results showed that the emergency service outside of the hospital had not been promoted formally. It made the participants expecting the realization of the system immediately. The hospital party revealed its intention to establish an emergency service system that appeared from the observable experiences of several victims' conditions. The traffic accident victims were accompanied by citizens and the other first responders. They might have been in poor conditions.

The establishment of a pre-hospital service is also the hope of the traffic police. The existence of pre-hospital services that can be carried out in an organized and integrated manner in one system will have an impact on coordination between agencies involved in handling traffic accident victims. This coordination will have a direct impact on the cooperation of the health team and other teams, so that if an accident occurs, all teams can go together to the location. This coordination is expected to result in a more effective handling process for the conditions of accident victims.

The same conditions occurred in Kampala and Uganda where the public is calling for immediate closeness to a formal and integrated emergency care system order [10, 14-16]. It is recognized that the outof-hospital response is important in the process of determining the prognosis of all injured patients. Appropriate response and short time intervals and adequate care are the most important goals of the emergency service system outside the hospital $[17,18]$.

It is said that mortality due to trauma that occurs outside the hospital can be higher in areas that do not have an emergency care system [8]. Therefore, it is hoped that an integrated emergency service system can be implemented immediately because the system can help in minimizing cases of death, injuries, disabilities, and morbidity caused by traffic accidents. However, this certainly requires support from a good emergency service system so that it can increase the provision of first aid for traffic accident victims [10]. Pre-hospital care that is carried out in an organized manner is proven to reduce mortality and disability that occurs due to emergency conditions [19].

\subsection{The first aid socialization of the accident victims for citizens}

When a traffic accident occurs, many parties in the location attempted to provide first aid as they can for the sake of the victims' survivability. The citizens around the traffic accident locations, the pedestrian, or the driers and bikers became the most involved parties in the accident location. It was frequently found that the administered aids were hindered by a lack of concerning knowledge of the administered actions. Several participants found during the traffic accident location complained about their lack of knowledge dealing with the first aid they should administer for the traumatic victims. This lack of knowledge in administering care for the victims raised their expectation to have medical parties to carry out the socialization program about first-emergency case aid. The applied socialization was expected to improve their knowledge so they would be able to administer better assistance for any traffic accident victims. It was stated by this following participant: 
"For me, the medical workers or the health agency officers should provide socialization activity for the citizens. It should deal with how to administer the first aid because (unclear voice of the participant) not all traffic accident cases could be attended by medical officers. This socialization is purposed to allow the citizens aware of how to administer the first aid. All of this is addressed for the sake of the victims to get a better aid." (F8)

The expectation dealing with socialization program about the first aid of emergency case due to traffic accidents is also stated by the society. A similar expectation was stated by the traffic unit. It was said that traffic accidents were unpredictable accidents. Thus, not all of them could be attended by medical workers or any trained first responders, such as the traffic unit. In several traffic accidents, the nearest people to the location did not administer any aid until the police officers arrived. The traffic unit officer expected society to be prepared by emergency knowledge. Thus, when an accident occurred, they should not wait for the traffic unit officers but they could administer their assistance, such as sending off the victims to the hospital.

"It is expected that, just in case, each medical officer on the field will provide socialization for the society. The point is when an accident occurs; they must not wait for police officers. Thus, when they see a traffic accident victim, they could directly send him to the hospital." (P5)

Those statements showed that in several cases, the first responders that were on the location had insufficient knowledge and skills. This condition triggers a waiting habit of society. They waited for the traffic unit officers to administer the first aid. It would hinder the victims to get immediate treatment after the accident. In this case, socialization dealing with first aid for the trauma victims due to accidents as required by society. The obtained knowledge and skills could be implemented when the people met a similar condition on the field. Thus, the first aid effort administered by the first responders could be supported by sufficient knowledge.

The results of this study are consistent with what had been done in Kampala metropolitan region. It was said that the related medication to the first aid for traffic accident victims was still insufficient. It made the victims severely injured and lost their lives before reaching the hospital. So, they did not have any opportunity to obtain more effective and professional care. The potential reason that causes such a situation is the lack of the first responders' skills in the accident location [10]. Lack of knowledge of the common people made them confused when they faced such an emergency occurrence. They did not know what to do or did not do anything in such a condition. Common people were not confident about what action they should administer for the first time to save the injured victims [20].

Traffic accidents were unpredictable accidents. Thus, not all of them could be attended by medical workers or any trained-first responders. The citizens became a temporary crowd after the accident in the location. The citizens became the first observers that plaid a direct role in providing aid with their various limited knowledge and skills. In several cases that happened in the citizens, they would wait for the traffic police unit to receive further instruction on the administered aids. In this situation, it became a hindrance to the traffic police unit. Thus, the unit hoped the citizens would be prepared by the emergency knowledge. It was expected that by having such knowledge, the citizens would directly administer aid without waiting for the traffic police unit.

By referring to several previous studies' findings, it could be stated that most traffic accident cases allowed common people to arrive first at the beginning than any other responders [20]. Common people that arrived on the spot several minutes after the traffic accidents, in more than $85 \%$ cases, played important roles in administering the first aid for the traffic accident victims (about 25-30\%) cases [21]. Consistent with the finding, it could be seen that several occurred cases had fewer of the participants to act and administer the first aid.

Realizing this phenomenon, there is a need for a socialization program as an effort to improve the common people's knowledge as the first responders to administer the first aid. It is expected by having sufficient knowledge concerning the first aid; the first responders in the location could take a role in administering the basic aid as what they have been informed. In the previous studies, they stated if the arrival of common people optimally could be used as the first responders. They had important roles to decrease complications due to the traffic accidents based on their knowledge obtained from the training [20].

\subsection{Training to administer first aid for the traffic accident victims}

In the effort to provide excellent-first aid for the traffic accident victims, the traffic unit expects cooperation with the health service. The traffic unit expected a regular-training program. Training dealing 
with emergency management is required in the effort to anticipate any fatality of trauma occurrence outside of the house. It was as stated here:

"Promote training between the hospital and the traffic unit so the hospital party could provide training for the traffic police units about how to provide the first aid correctly and to stop an individual's bleeding. Thus, we can anticipate any further fatalities." (P2)

Training concerning with the first aid for traffic accident victims becomes the hope of several participants. In this case, the traffic police unit expected cooperation from related institutions to promote a join-training with the health institution. The applied training is expected to have a contribution and improve the knowledge of the traffic police unit to help the victims. In a study, it was revealed that common people had incorrect judgment when an accident occurred. It was due to a lack of training about what they had to do when they dealt with a traffic accident [22]. Therefore, it is expected to have a join-training about the first aid of trauma victims.

From the findings, it could be found that the traffic police unit had joined an emergency management training process that was held by the police institution. The training obtained from the police institution was promoted consecutively for a long time. By referring to the existing condition, the traffic police unit expected to cooperate with the health service. Thus, they could provide training for traffic police unit members. The cooperation is expected to be realized into scheduled and sustainable training. Thus, the latest knowledge could be updated at every moment, especially for administering care for traumatic cases that frequently occur outside of the hospital.

The training concerning the basic emergency aid for the traffic police unit would contribute to the success of traffic accident victim care outside of the hospital. It was said that training and improving skills concerning traumatic care outside of the hospital caused common people to be more confident in administering the required intervention to aid injured victims [20]. The $43 \%$ of the trained common people took action while administering the first aid. $89 \%$ of common people tended to assist the victims than those untrained [23].

Common people as the first responders in the location had been trained in administering aid for traumatic injuries or they had followed a first aid course. Those people were more responsive to provide aid for the victims due to the traffic accident. Besides that, they might provide more appropriate intervention in the accident location [24-26]. It was stated that formal training could improve the participants' practices in providing the first aid [27]. In the regions that have had any emergency pre-hospital service formally with untrained first responders, the first thing to do is teaching those common people about the basics of the first aid [28] thus they could be better first responders in providing emergency care.

\subsection{The socialization of the health care service emergency number}

The communication media of the emergency was frequently complained by the participants in the middle of the experienced emergency state condition. This condition led to the confusion they experienced during facing a traffic accident case as stated below:

"Yup, there should be a media or community that we can contact when a traffic accident occurs. It should not be like now. When a traffic accident occurs, we do not know who we should contact." (P2)

The hindrances in emergency communication were also complained by several participants. The participants experienced a lack of socialization dealing with the health service contact number. Therefore, the participants thought it was important to be informed through socialization for all citizens, especially the emergency ambulance contact number. It should be contactable when an accident occurs. It was as stated below:

"It should be socialized for village citizens about the important numbers of hospitals, such as ambulance that could be contacted immediately. Thus, when an accident occurs, the emergency numbers could be contacted. We could directly contact the hospital because from what I saw, the most frequently arrived in the location was the police officer care units instead of an ambulance." (P6)

The pre-hospital service system, in this case, was PSC 119 unit. It was expected to be immediately promoted. The promoted PSC 199 system was an effort to suppress the mortality rate of emergency state condition victims. The existence of PSC 119 could finally foster the emergency state communication system in which its promotion was accessible for every element. From several utterances of the participants, it was implicitly stated the expectation of the hospital party as the health service providers to inform the accessible 
emergency ambulance contact numbers for all social elements. Thus, it would be useful when an emergency case occurred outside of the hospital.

The emergency communication system has become an important matter of a pre-hospital service. The communication system is a part of an emergency service that is required by all first-responders in the accident location. During the accident, the emergency communication system could be applied to ask health team assistance and safe transportation to take the accident victims. The communication media of the emergency was frequently complained by the participants in the middle of the experienced emergency state condition. Such conditions cause the participants to act as what they can do with their existing knowledge. Besides that, the participants would take the patients by any vehicle because there were no vehicle accesses, such as a contactable ambulance.

When the participants did not have a communication community, they would act anything without any direction from the professionals. The participants would also have roles to send off the victims in which did not take an ambulance. They would take any transportation in the field. The previous studies found difficulties dealing with communication, such as the emergency call channel that was not available. It contributed to the hindrance of administering the first aid for the emergency case [29].

Other studies showed that besides providing training for larger common people as the first responders, there were also several necessities to meet. Constructing the infrastructure to promote care outside of the hospital needed attention. It was such as providing the contactable service provider contact number to improve the access and utilization of the ambulance [30]. A contact number must be known by all communities. The citizens preferred to have broader knowledge concerning the emergency call. It was done because of the emergency call number and it was an important thing in supporting the health service [31].

\section{CONCLUSION}

Several expectations of the participants are establishing the pre-hospitalized emergency service, socializing the first aid for the incident victims, training dealing with the first aid of taking care trauma victims, and promoting socialization for all citizens about the emergency numbers of health service institution which could be immediately contacted when an accident occurs. Therefore, there is a need for an emergency service system establishment and development. The development and establishment have a function to prepare the society, police officer, and other volunteers with the basic aid to administer care on the spot for the traumatic patients; to prepare the safe transportations, and to massively broadcast the emergency contact number of the hospital ambulances for every society's element.

\section{ACKNOWLEDGEMENTS}

The authors would like to thank all the study participants and stakeholders involved in this research.

\section{REFERENCES}

[1] Pigoga, J.L., et al., "Adapting the emergency first aid responder course for Zambia through curriculum mapping and blueprinting," BMJ Open, vol. 7, no. 12, p. e018389, 2017.

[2] Vakili, M.A., et al., "The efficacy of a first aid training course for drivers: an experience from northern Iran," Chinese Journal Of Traumatology, vol. 17, no. 5, pp. 289-292, 2014.

[3] Goonewardene, S.S., et al., "Road traffic collisions-case fatality rate, crash injury rate, and number of motor vehicles: time trends between a developed and developing country," The American Surgeon, vol. 76, no. 9, pp. 977-981, 2010.

[4] Polri, K., Jumlah Kecelakaan Lalulintas, 2018, Korps Lalulintas Kepolisian Negara Republik Indonesia: Indonesia.

[5] Elmqvist, C., et al., "Being first on the scene of an accident-experiences of 'doing'prehospital emergency care," Scandinavian Journal of Caring Sciences, vol. 24, no. 2, pp. 266-273, 2010.

[6] Chokotho, L., et al., "First responders and prehospital care for road traffic injuries in Malawi," Prehospital And Disaster Medicine, vol. 32, no. 1, pp. 14-19. 2017.

[7] Calvello, E., et al., "Emergency care in sub-Saharan Africa: results of a consensus conference," African Journal of Emergency Medicine, vol. 3, no. 1, pp. 42-48, 2013.

[8] Debenham, S., et al., "Where there is no EMS: lay providers in Emergency Medical Services care-EMS as a public health priority," Prehospital and Disaster Medicine, vol. 32, no. 6, pp. 593-595, 2017.

[9] Beuran, M., et al., "Prehospital trauma care: a clinical review," Chirurgia, vol. 107, no. 5, pp. 564-570, 2012. 
[10] Balikuddembe, J.K., et al., "Weaknesses and capacities affecting the Prehospital emergency care for victims of road traffic incidents in the greater Kampala metropolitan area: a cross-sectional study," BMC Emergency Medicine, vol. 17, no. 1, 2017.

[11] Khorasani-Zavareh, D., et al., "Post-crash management of road traffic injury victims in Iran. Stakeholders' views on current barriers and potential facilitators," BMC Emergency Medicine, vol. 9, no. 1, 2009.

[12] Hall, A., K. Wooton, and A. Hutton, "Bystander Experiences at and after a Motor Vehicle Accident: A review of the literature," Australasian Journal of Paramedicine, vo. 10, no. 4, 2013.

[13] Djalali, A., et al., "Facilitators and obstacles in pre-hospital medical response to earthquakes: a qualitative study," Scandinavian Journal of Trauma, Resuscitation and Emergency Medicine, vol. 19, no. 1, pp. 1-9, 2011.

[14] Hsia, R.Y., et al., "Epidemiology of injuries presenting to the national hospital in Kampala, Uganda: implications for research and policy," International Journal of Emergency Medicine, vol. 3, no. 3, pp. 165-172, 2010.

[15] Jayaraman, S., et al., "Current patterns of prehospital trauma care in Kampala, Uganda and the feasibility of a layfirst-responder training program," World Journal of Surgery, vol. 33, no. 12, pp. 2512-2521, 2009.

[16] Kigera, J.W.M. and E.K. Naddumba, "Injury to presentation delays among musculoskeletal trauma patients in Uganda," East African Orthopaedic Journal, vol. 5, no. 2, pp. 36-39, 2011.

[17] Concannon, T.W., et al., "Elapsed time in emergency medical services for patients with cardiac complaints: are some patients at greater risk for delay?," Circulation: Cardiovascular Quality and Outcomes, vol. 2, no. 1, pp. 9$15,2009$.

[18] Wilde, E.T., "Do emergency medical system response times matter for health outcomes?" Health Economics, vol. 22, no. 7, pp. 790-806, 2013.

[19] Wesson, H.K.H. and M. Kwong, "Trauma care in India: A review of the literature," Surgery, vol. 162, no. 6, pp. S85-S106, 2017.

[20] Heidari, M., A. Aryankhesal, and D. Khorasani-Zavareh, "Laypeople roles at road traffic crash scenes: a systematic review," International Journal of Injury Control and Safety Promotion, vol. 26, no. 1, pp. 82-91. 2018.

[21] Oliver, G., D. Walter, and A. Redmond, "Prehospital deaths from trauma: Are injuries survivable and do bystanders help?" Resuscitation, vol. 106, p. e92, 2016.

[22] Hadigal, S. and G.R. Rao, "Study of mob-behavior during road traffic accidents in Hyderabad," Transforming Emergency Management, vol. p. 8-19, 2011.

[23] Bakke, H.K., et al., "A nationwide survey of first aid training and encounters in Norway," BMC Emergency Medicine, vol. 17, no. 1, p. 6, 2017.

[24] Arbon, P., J. Hayes, and R. Woodman, "First aid and harm minimization for victims of road trauma: a population study" Prehospital and Disaster Medicine, vol. 26, no. 4, pp. 276-282, 2011.

[25] Bakke, H.K., et al., "Bystander first aid in trauma-prevalence and quality: a prospective observational study," Acta Anaesthesiologica Scandinavica, vol. 59, no. 9, pp. 1187-1193, 2015.

[26] Bazeli, J., A. Aryankhesal, and D. Khorasani-Zavareh, "Exploring the perception of aid organizations' staff about factors affecting management of mass casualty traffic incidents in Iran: a grounded theory study," Electronic Physician, vol. 9, no. 7, pp. 4773-4779, 2017.

[27] Pallavisarji, U., G. Gururaj, and R.N. Girish, "Practice and perception of first aid among lay first responders in a southern district of India," Archives of Trauma Research, vo. 1, no. 4, pp. 155-160, 2013.

[28] Kobusingye, O.C., et al., "Emergency medical systems in low-and middle-income countries: recommendations for action," Bulletin of the World Health Organization, vol. 83, no 8, pp. 626-631, 2005.

[29] Broccoli, M.C., et al., "Perceptions of emergency care in Kenyan communities lacking access to formalised emergency medical systems: a qualitative study," BMJ Open, vol. 5, no. 11, pp. e009208, 2015.

[30] Hofman, J.J., et al., "Motorcycle ambulances for referral of obstetric emergencies in rural Malawi: do they reduce delay and what do they cost?" International Journal of Gynecology \& Obstetrics, vol. 102, no. 2, pp. 191-197, 2008.

[31] Stein, C., et al., "Access to out-of-hospital emergency care in Africa: consensus conference recommendations," African Journal of Emergency Medicine, vol. 6, no. 3, pp. 158-161, 2016. 